\title{
Transcutaneous nitroglycerin in the treatment of erectile dysfunction in spinal cord injured
}

\author{
J Sønksen MD ${ }^{1}$ F Biering-Sørensen $\mathrm{MD}, \mathrm{PhD}^{2}$ \\ ${ }^{1}$ Department of Urology, ${ }^{2}$ Centre for Spinal Cord Injured, Rigshospitalet, University of \\ Copenhagen, Blegdamsvej 9, DK-2100 Copenhagen, Denmark.
}

We have tested the erectile effect of penile applicated nitroglycerin plasters (Transiderm-Nitro $10 \mathrm{mg} / 24$ hours) in 17 spinal cord injured men, who had responded to intracavernous papaverine injections with erections sufficient for vaginal penetration. The nitroglycerin plasters were applied on the skin of the penile shaft and a positive response was obtained in 12 men. A total of 5 men reported an erectile response sufficient for vaginal penetration after using nitroglycerin plasters at home. All 5 preferred to continue with this noninvasive treatment compared to papaverine injections. Our results indicate that men with spinal cord injury who need doses larger than $15 \mathrm{mg}$ papaverine to obtain erection sufficient for vaginal penetration will not achieve this with nitroglycerin plasters.

We suggest that this noninvasive treatment should be tested on spinal cord injured men before injection therapy is initiated.

Key words: spinal cord injury; impotence; nitroglycerin.

\section{Introduction}

The pharmacological treatment of erectile dysfunction in spinal cord injured men has previously been based primarily on intracavernous injections of papaverine ${ }^{1-4}$ or a combination of papaverine and phentolamine. , $3,5,6^{2}$

Intracavernous injections of vasoactive drugs in the treatment of erectile dysfunction do, however, also have side effects and drawbacks such as prolonged erection, haematoma or fibrosis in the corporal tissue. ${ }^{7}$

Because of the potential complications caused by the injection therapy and the positive results obtained by Claes and Baert $^{8}$ in impotent men using penile application of nitroglycerin plasters, we found it of interest to test the erectile effect of these plasters in a group of spinal cord injured men, who had had erections sufficient for vaginal penetration when using papaverine injections.

\section{Materials and methods}

Seventeen men aged 19-51 years (median age 41 years) with spinal cord lesions 1-27 years (median 7 years) previously entered the study. Neurological levels of the lesions ranged from $\mathrm{C} 2$ to $\mathrm{L} 4,13$ complete and 4 incomplete. Only participants who had obtained erections sufficient for vaginal penetration after papaverine injections were included. Papaverine doses had ranged from 5 to $60 \mathrm{mg}$.

We used the Transiderm-Nitro plaster $10 \mathrm{mg} / 24$ hours (CIBA-Geigy) containing $50 \mathrm{mg}$ glyceryli nitras, a powerful smooth muscle relaxant of which $10 \mathrm{mg}$ is absorbed during 24 hours. Glyceryli nitras easily penetrates healthy skin and a constant plasma level from 2-24 hours is seen when the plaster is applied on the chest. The half life of the plasma nitroglycerin concentration following removal of the plaster is almost one hour. However, the pharmacokinetics in connection with penile application are not known.

The size of the plaster is $32 \times 89 \mathrm{~mm}$ and absorption takes place from a $20 \mathrm{~mm}^{2}$ area. The plaster is available in Denmark without prescription at the price of approximately DKK $16(£ 1.50)$.

Initially, a nitroglycerin test was conducted in the outpatient clinic. We placed 
the plaster around the penile shaft for 1-2 hours depending on the erectile response obtained. Before removal of the plaster penile stasis was applied for 10 minutes.

The long pubic hairs should be cut if necessary to prevent interference with the plaster attachment.

The result of the nitroglycerin test was classified clinically into 3 categories as follows: complete response: an erection with full rigidity; partial response: an erection with some rigidity and/or tumescence; and failure: no noticeable erection.

When a complete or partial response was obtained, the participant was given 5 plasters for domestic use together with a questionnaire to be completed after each application. The questionnaire included items regarding the erectile response, whether the erection was sufficient for vaginal penetration, side-effects, and whether in the future they preferred nitroglycerin plasters or papaverine injections to obtain erection.

\section{Results}

The nitroglycerin test was positive in 12 of 17 participants: 5 had complete and 7 partial responses whereas 5 failed to respond. Median plaster application time to the observed response was $75 \mathrm{~min}$. Duration of the erections in the group with complete responses ranged from 20 to 45 minutes after removal of the plasters.

In Table I the participants' age, years since lesion and level of spinal cord lesion are related to the results of the nitroglycerin test.

Figure 1 compares the doses of papaverine required to obtain an erection sufficient for vaginal penetration with the results of the nitroglycerin test.

\section{NITROGLYCERIN TEST}

$(\mathrm{N}=17)$

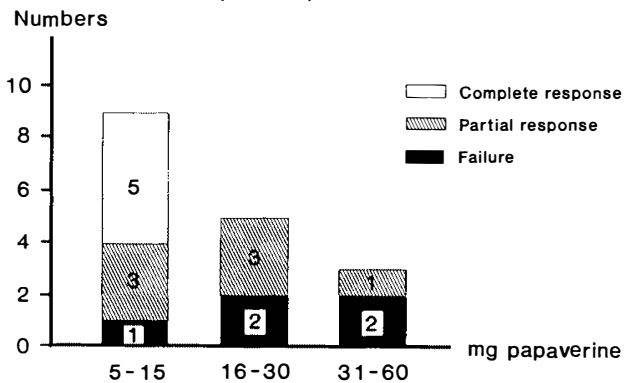

Figure 1 Doses of papaverine required to obtain an erection sufficient for vaginal penetration compared to the results of the nitroglycerin test.

The 12 participants who obtained a positive response to the nitroglycerin test continued to use the plasters at home and have tested 5 plasters each.

Based on the subjective evaluations reported in the questionnaires completed after each application, it appeared that 5 (29\%) participants obtained an erectile response to plaster application sufficient for vaginal penetration. These 5 participants originated from the group requiring $5-15 \mathrm{mg}$ papaverine and 4 of the 5 were from the group obtaining complete response during the nitroglycerin test whereas one was from the group with only partial response. They all preferred to continue with nitroglycerin plasters compared to papaverine injections.

In total, 6 participants experienced headaches following plaster application but only 2 required treatment with mild analgesics (ie paracetamol). No other side effects were observed or reported, including autonomic dysreflexia.

Table I Results of nitroglycerin test related to the participants' age, years since lesion and level of spinal cord lesion

\begin{tabular}{|c|c|c|c|c|c|}
\hline \multirow{2}{*}{$\begin{array}{l}\text { Results of the } \\
\text { nitroglycerin test }\end{array}$} & \multicolumn{2}{|c|}{ Age (years) } & \multicolumn{2}{|c|}{ Years since lesion } & \multirow{2}{*}{$\begin{array}{l}\text { Level of lesion } \\
\text { range }\end{array}$} \\
\hline & median & (range) & median & (range) & \\
\hline Complete response $(n=5)$ & 41 & $(27-51)$ & 8 & $(4-24)$ & $\mathrm{C} 6-\mathrm{T} 7$ \\
\hline Partial response $(n=7)$ & 28 & $(19-50)$ & 4 & $(1-10)$ & T6-L4 \\
\hline Failure $(\mathrm{n}=5)$ & 43 & $(29-45)$ & 21 & $(7-27)$ & $\mathrm{C} 2-\mathrm{T} 10$ \\
\hline
\end{tabular}




\section{Discussion}

Owen et $a l^{9}$ reported from a placebo-controlled study on 26 impotent subjects, a significant increase of the penile circumference (strain gauge technique) in 18 patients after penile application of nitroglycerin paste and visual sexual stimulation. A randomized placebo-controlled study by Claes and $\mathrm{Baert}^{8}$ in a group of 26 impotent men showed that with nitroglycerin plasters ( $10 \mathrm{mg} / 24$ hours) 12 returned to satisfactory sexual function with erections adequate for vaginal penetration while 9 reported some improvement in the quality of erection, but insufficient to restore satisfactory sexual performance. In one patient potency was restored after the application of placebo plasters. Neither of these studies reported inclusion of patients with neurogenic impotence.

Meyhoff et al $^{10}$ tested 10 patients with various etiologies of impotence including neurogenic, but apparently none with spinal cord injury. In this non double-blind nor placebo-controlled study, it was found that Transiderm-Nitro plaster $(10 \mathrm{mg} / 24$ hours $)$ lead to an erectile response of all patients in the nitroglycerin test and satisfactory potency was restored in 4 patients following self administration.

It seems attractive to test a noninvasive treatment for all men with erectile dysfunction including the group of spinal cord injured men for several reasons. Prolonged erection following intracavernous injection is the most common side effect, and the risk of developing subcutaneous haematomas at the site of injection and fibrosis in the corporal tissue as a result of numerous injections are further problems. ${ }^{7}$ The participants are also concerned about these problems and unknown long term adverse effects. $^{11}$ In our experience, papaverine injection is stress inducing and for some too 'technical' and therefore unacceptable.

According to Table I there is no relation between age or level of lesion and the results of the nitroglycerin test. However, the nitroglycerin test shows a relatively high median number of years since lesions in the failure group but no conclusion can be based on such small numbers.

A comparison of the doses of papaverine required to obtain an erection sufficient for vaginal penetration with the results of the nitroglycerin test indicates that participants who need doses larger than $15 \mathrm{mg}$ of papaverine to obtain erection sufficient for vaginal penetration will not achieve a complete response with nitroglycerin plasters (Fig 1).

Nitroglycerin plasters have well known side effects, primarily related to allergic dermatitis, ${ }^{12}$ headache and postural dizziness related to orthostatic hypotension. ${ }^{13}$ In total 6 participants experienced headache during the test phase but only 2 cases required treatment with mild analgesics (ie paracetamol). We found no relation between the level of lesion, whether complete or incomplete, and the occurrence of headache.

Meyhoff et $a l^{10}$ have reported that mild analgesics taken one hour before plaster application may prevent headache. In our study, however, none of the 5 participants obtaining erection sufficient for vaginal penetration reported any headaches linked with the plaster applications at home.

In conclusion, the present results indicate that transcutaneous nitroglycerin therapy may be an interesting choice of treatment for some spinal cord injured men with erectile dysfunction.

Based on the fact that Transiderm-Nitro plasters are easy to apply and test and seem to have no serious side effects, we believe that this noninvasive treatment should be tested on spinal cord injured men before injection therapy in initiated.

\section{Acknowledgement}

Ciba-Geigy A/S, Denmark, provided the patients included in the study with TransidermNitro plasters free of charge.

\section{References}

1 Beretta G, Zanollo A, Fanciullacci F, Catanzaro F (1986) Intracavernous injection of papaverin in paraplegic males. Acta Europaea Fertilitatis 17: 283-4. 
2 Bodner DR, Lindan R, Leffler E, Kursh ED, Resnick MI (1987) The application of intracavernous injection of vasoactive medications for erection in men with spinal cord injury. J Urol 38: 310-1.

3 Sidi AA, Cameron JS, Dykstra DD, Reinberg Y, Lange PH (1987) Vasoactive intracavernous pharmacotherapy for the treatment of erectile impotence in men with spinal cord injury. $J$ Urol 138: 539-42.

4 Virag R, Sussman H, Floresco J, Shoukry K (1987) Late results on the treatment of neurogenic impotence by selfintracavernous injection (SICI) of vasoactive drugs. World J Urol 5: 166-70.

5 Lloyd LK, Richards JS (1989) Intracavernous pharmacotherapy for management of erectile dysfunction in spinal cord injury. Paraplegia 27: 457-64.

6 Wyndaele JJ, de Meyer JM, de Sy WA, Claessens H (1986) Intracavernous injection of vasoactive drugs, an alternative for treating impotence in spinal cord injury patients. Paraplegia 24: 271-5.

7 Jünemann K, Alken P (1989) Pharmacotherapy of erectile dysfunction: a review. Int J Impotence Res 1: 71-93.

8 Claes, H Baert L (1989) Trancutaneous nitroglycerin therapy in the treatment of impotence. Urol Int 44: $309-12$.

9 Owen JA, Saunders F, Harris C et al (1989) Topical nitroglycerin: a potential treatment for impotence. J Urol 141: 546-8.

10 Meyhoff $\mathrm{HH}$, Rosenkilde P. Bødker A (1992) Non-invasive management of impotence with transcutaneous nitroglycerin. Br J Urol 69: 88-90.

11 Sidi AA, Reddy PK, Chen KK (1988) Patient acceptance of and satisfaction with vasoactive intracavernous pharmacotherapy for impotence. J Urol 140: 293-4.

12 Sausher WF, Frederick FD (1978) Allergic contact dermatitis secondary to topical nitroglycerin. $J A M A$ 239: $1743-4$.

13 Abrams J (1980) Nitroglycerin and long-acting nitrates. N Engl J Med 32: 1234-7. 